\section{PO-0985 VITAMIN D DEFICIENCY IN THE HIGH RISK SOMALI COMMUNITY IN WEST LONDON: PHASE I UNDERSTANDING THE COMMUNITY}

R Tewari, MK Dhingra. River Island Academic Centre for Paediatrics and Child Care, Northwick Park and St Marks Hospital, London, UK

\subsection{6/archdischild-2014-307384.1602}

Background and aims There is increasing evidence that childhood vitamin D deficiency is associated with poorer overall health and associated with numerous diseases. We wanted to assess knowledge and use of vitamin D in mothers of the Somali Community in West London with the aim of improving knowledge, access to vitamin D and reducing the burden of vitamin D associated healthcare problems in mothers and their children.

Methods A representative sample of Somali individuals were contacted by HASVO (Harrow Association of Somali Voluntary Organisations) and three meetings conducted with these community members. Participants were asked to complete a detailed vitamin $\mathrm{D}$ questionnaire assessing baseline knowledge of vitamin D deficiency, awareness of its importance and current uptake. This was followed by an educational presentation and discussion. Questionnaires and presentations were in English and translators provided for those who required assistance.

Results 45 participants completed the questionnaire. Most participants had heard of vitamin D deficiency (33), but the participants and their children were at high risk of it through lifestyle factors, particularly low sun exposure. The discussion exposed variability in both lay health beliefs and experiences with healthcare professionals.

Conclusion Phase I of this study has shown that (i) there is a current vitamin D crisis in this community and knowledge is variable, (ii) clearer community information is needed about vitamin D dosage, (iii) access to cheap vitamin $\mathrm{D}$ needs to be better publicised. Thus, we propose that a vitamin D campaign is needed and will be rolled out in Phase II.

\section{P0-0986 INVESTIGATION AND MANAGEMENT OF VITAMIN D DEFICIENCY/INSUFFICIENCY-A SERVICE EVALUATION}

M Ahmed, DN Sobithadevi. Paediatrics, Burton Hospitals NHS Foundation Trust, Burton on Trent, UK

\subsection{6/archdischild-2014-307384.1603}

Introduction Vitamin D is essential for bone and skeletal health. The major natural source of Vitamin D is from skin exposure to sunlight. Current evidence suggests that there isn't enough ambient ultraviolet sunlight from October to April in UK (UK). Similarly, there are reports of rickets re-emerging in parts of UK. There is no internationally agreed consensus regarding cut off value denoting Vitamin D insufficiency/deficiency. Variable practice exits in treating symptomatic and asymptomatic children with Vitamin D insufficiency/deficiency.

Aim To evaluate our current practice in investigating and managing children with subnormal Vitamin D levels ( $<50 \mathrm{nmol} / \mathrm{l})$.

Method We carried out a retrospective data review on all patients $<17$ years of age who had vitamin D levels checked in a District General Hospital setting. Data was collected from 20082012 and analysed using Microsoft excel.

Results Vitamin D levels were checked on 136 occasions in 89 patients $(60 \%$ male). $41 \%$ of the values were above $50 \mathrm{nmol} / \mathrm{l}$ while $20 \%$ were $<20 \mathrm{nmol} / \mathrm{l}$. $\sim 3 / 4$ values of $<20 \mathrm{nmol} / 1$ were from children of Indian and Pakistani origin. $80 \%$ of patients with values $<50$ were treated with oral Vitamin D supplementation. Treatment dose varied from 400-10000 IU/day to 20000$40000 \mathrm{IU} /$ week (ergocalciferol or cholecalciferol).

Conclusion Our data reiterates lack of unified guidance and variable practice amongst clinicians managing Vitamin D deficiency/ insufficiency. Careful attention is required when managing South Asian children with chronic illnesses. There is urgent need for multicentre/national research and unified guideline for prevention and treatment of Vitamin D deficiency in children.

\section{PO-0987 FEVER IN CHILDREN WITH ACUTE RESPIRATORY INFECTIONS: PRACTICES AND RECOMMENDATIONS}

A Holban, N Revenco, L Romanciuc, O Turcu. Pediatrics, State Medical and Pharmaceutical University Nicolae Testemitanu, Chisinau, Moldova

\subsection{6/archdischild-2014-307384.1604}

Aim To assess treatment practices versus recommendations for fever treatment in children with acute respiratory infections (ARI).

Material and methods We analysed 189 clinical records of children hospitalised with ARI, aged from 4 mounts to 7 years: 4 12 mounts $-23.8 \% ; 1-3$ years $-67.7 \%$ and older than 3 years - $8.5 \%$ children. The exclusion criteria were: children under 3 months; congenital malformations or chronic diseases; history of febrile seizures. The review included treatment of febrile syndrome in different stages of paediatric healthcare (home treatment, primary medical care and in hospital).

Results Results of the research revealed many deficiencies in therapeutic management of the febrile syndrome: in 28\% cases was an inappropriate use of antipyretic drugs by caregivers (at body temperatures below $38^{\circ} \mathrm{C}$ ); the adequate rehydration of children with fever was provided only in $22 \%$ of children; Metamisole was used in $23.4 \%$. The source of information for parents regarding the treatment of children with fever was not always the doctor; many parents followed the advices from their relatives, friends and pharmacist. Family doctors and paediatricians were consulted in only $43.9 \%$ and $10.1 \%$ cases, respectively.

Conclusions Results of the study showed that the existing practices in the fever treatment in children with ARI are explained by low level of information of caregivers regarding the care of a sick child at home and some divergence between international and national recommendations for fever management in children.

\section{PO-0988 HOW TO PREVENT AND IMPROVE MANAGEMENT OF IRON DEFICIENCY ANAEMIA IN CHILDREN}

CS Chew, XY Chin, GH Tan, SY Chang, MC Tan, CM Lam. Paediatrics Medicine, KK Women's and Children's Hospital, Singapore, Singapore

\subsection{6/archdischild-2014-307384.1605}

Aims The aim of our retrospective chart review is to identify causes and improve management of iron deficiency anaemia (IDA) amongst toddlers in outpatient paediatric clinics.

Methods This is a retrospective chart review of children, aged 6 months to 2 years old, who were diagnosed with IDA over 1 year study period in outpatient clinics. Identification of cases with iron deficiency anaemia were from outpatient pharmacy who were prescribed iron supplements during the study period. 
Results Over the study period, 52 cases of iron deficiency anaemia were diagnosed. Mean age of the cases was 11 months old and the mean haemoglobin level was $10 \pm 1.4 \mathrm{~g} / \mathrm{Dl}$ at diagnosis. Children on complete breastfeeding have a significantly lower haemoglobin compared to those on mixed or formula feeding ( $\mathrm{p}$ $=0.01$ ).

Thalassaemia screen were positive in 14 out of 32 cases screened. Mentzer index was significantly lower in patients with positive thalassaemia screen versus patients without thalassaemia ( $\mathrm{p}=0.00)$.

Patients referred to dietician showed a significant improvement in haemoglobin compared to those who were not referred. $(\mathrm{p}=0.16)$ Compliance to iron administration were assessed in 29 cases, with 6 were assessed to be non-compliant. Patients who were compliant to iron supplements showed a non-significant improvement in haemoglobin compared to those who were non-compliant $(\mathrm{p}=0.5)$.

Conclusion Mentzer index is useful to distinguish between IDA and thalassaemia. Assessing compliance and involving dietician are important factors in improving haemoglobin levels. Children on complete breastfeeding should be advised on iron rich diet or regular iron supplementation.

\section{Primary Care and General Paediatrics}

\section{PO-0989 ECTODERMAL DYSPLASIAS: TWISTS IN AN OLD TALE}

${ }^{1} \mathrm{~N}$ Boutrid, ${ }^{1} \underline{\mathrm{H} \text { Rahmoune, }}{ }^{2} \mathrm{M}$ Amrane, ${ }^{1} \mathrm{~B}$ Bioud. ${ }^{1}$ Pediatrics, Child and Mother Hospital, Setif, Algeria; ${ }^{2}$ Biochemistry, University Hospital, Setif, Algeria

10.1136/archdischild-2014-307384.1606

Introduction Ectodermal dysplasia (ED) are hereditary disorders involving congenital anomalies of different ectodermal structures, the most prominent being the adontia/hypodontia.

We present several cases: isolated, associated and syndromic. Methods and description The examination of affected children revealed in all cases rare bevel teeth, delayed and abnormal teething, with a thin and patchy hair with rare eyelashes and eyebrows

The examination confirms asudoral hyperthermia episodes at young age

Five children (two brothers and 3 other from different families) consult for delayed dentition with tapered appearance of their few teeth (quantitatively and qualitatively defective) and present with facial dysmorphism, fine hair.

Another boy has, in addition, skin xerosis with difficult to control intermittent asthma, probably associated with immune deficiency. The last patient, also a male one has, in addition to DE, a congenital hypothyroidism and cleft palate. In all our patients, dental panoramic radiograph confirms the diagnosis. Results and Discussion The ED are inherited disorders OMIM 305100, locus Xq12-Q13.1 involving dental conditions, glands and skin appendages (hair and nails), with an estimated frequency $<10 / 100,000$ live births. The recessive transmission (autosomal or X-linked) is to be determined by molecular genetics. The risk of associated anomalies (including immune deficiency) is to be highly considered.

Management is symptomatic: orthodontics, eviction from heat and fever treatment, application of emollients to skin.

Conclusion DE are hereditary embryopathies affecting the teeth and other structures derived from the ectoderm. Diagnosis is clinical, confirmed by radiology. The treatment is, up to now, only symptomatic.

\section{P0-0990 PREVALENCE OF ALLERGIC RHINITIS IN CHILDREN'S POPULATION - ADJARA REGION}

${ }^{1} \mathrm{~N}$ Adamia, ${ }^{1} \mathrm{~N}$ Manjavidze, ${ }^{2} \mathrm{M}$ Ghughunishvili, ${ }^{1} \mathrm{I}$ Ubiria, ${ }^{2} \mathrm{~L}$ Saginadze, ${ }^{3} \mathrm{~N}$ Katamadze, ${ }^{4} \mathrm{~V}$ Zerekidze, ${ }^{4} \mathrm{~T}$ Gigauri, ${ }^{2} \mathrm{~T}$ Arakhamia, ${ }^{1} \mathrm{~N}$ Gogodze, ${ }^{1} \mathrm{~V}$ Kvantaliani, ${ }^{5} \mathrm{~L}$ Jorjoliani. ${ }^{1} \mathrm{Tbilisi}$ State Medical University, Tbilisi, Georgia; ${ }^{2}$ M. Iashvili Children's Central Hospital, Department of General Pediatrics, Tbilisi, Georgia; ${ }^{3}$ Center of Family Medicine, Department of Pediatrics, Batumi, Georgia; ${ }^{3}$ Clinical Allergy and Immunology Center of Kutaisi, Department - General Pediatrics, Allergology, Kutaisi, Georgia; ${ }^{4}$ Pediatric Institute, Tabilsi, Georgia; ${ }^{5}$. Javakhishvili State University, Department of Pediatrics, Tbilisi Georgia; ${ }^{6}$ Medical Center "Healthy Future", Tabilsi, Georgia

\subsection{6/archdischild-2014-307384.1607}

Allergy and allergic diseases comprise the global problem of public health care all over the world. In general structure of allergies' morbidity share of allergic rhinitis is quite high. Its prevalence in children's population varies within 15-25\% (ARIA). All the above determined the goal of our work.

Goal Goal of our work is study of prevalence of allergic rhinitis in children's population of Adjara Region.

Materials and methods For the first stage of study we developed the questionnaire. Studied population included 1237 children from 4 to 15 years age (511 girls and 726 boys). Screening was conducted by means of the initial questionnaire oriented towards first diagnostics of allergic rhinitis. Second stage included clinical-allergic study. This stage included also study of IgR level in blood serum and prick-test in vivo (included food, plants, epidermal and domestic allergens). Data processing was provided by means of SPSS9v12.5 software package.

Results First stage of the study showed that of symptoms of allergic rhinitis $9.8 \%$ of the studied population had sneezing, $14.5 \%$ - rhinorrhea, $13.9 \%$ - nasal obstruction, $15.55 \%$ - nasal itch and the mentioned symptoms, in $4.5 \%$ of cases were accompanied with lacrimation and eye itch. Respondents with AR symptoms (236) indicated seasonal nature of the disease. At the second stage of study, on the basis of the frequency, characteristics and set of clinical signs, in $56.7 \%$ of patients intermittent and in $43.3 \%$ of patients - persistent allergic rhinitis was diagnosed. Prevalence of symptoms was reliably higher among the boys, compared with the girls $(\mathrm{p}<0.05)$

Conclusion Epidemiological study of allergic rhinitis in children's population of Batumi, Adjara, showed that AR prevalence was $15.3 \%$, rarely with accompanying conjunctivitis (4.5\%). High frequency of late diagnostics was identified $(\mathrm{p}<0.05)$.

\section{PO-0991 FOOD ALLERGY EPIDEMIOLOGY IN CHILDREN'S POPULATION}

${ }^{1} \mathrm{~N}$ Adamia, ${ }^{2} \mathrm{M}$ Ghughunishvili, ${ }^{1} \mathrm{I}$ Ubiria, ${ }^{2} \mathrm{~L}$ Saginadze, ${ }^{3} \mathrm{~N}$ Katamadze, ${ }^{2} \mathrm{~T}$ Arakhamia, ${ }^{1} \mathrm{~N}$ Gogodze, ${ }^{2} \mathrm{~V}$ Kvantaliani, ${ }^{1} \mathrm{~L}$ Jorjoliani, ${ }^{4} \mathrm{D}$ Khachapuridze, ${ }^{1} \mathrm{I}$ Chkhaidze, ${ }^{2} \mathrm{M}$ Surviladze. ${ }^{1}$ Tbilisi State Medical University, Tbilisi, Georgia; ${ }^{2} M$. Iashvili Children's Central Hospital, Department of General Pediatrics, Tbilisi, Georgia; ${ }^{3}$ Center of Family Medicine, Department of Pediatrics, Batumi, Georgia; ${ }^{4}$ Clinical Allergy and Immunology Center of Kutaisi, Department - General Pediatrics, Allergology, Kutaisi, Georgia

\subsection{6/archdischild-2014-307384.1608}

Share of food allergies is quite high in the general structure of allergy morbidity (varies between $0.1 \%$ and $7 \%$ ). Allergy diseases comprise global problem of public health care system. 